\title{
Use Patterns and Costs of Isolated Limb Perfusion and Infusion in the Treatment of Regional Metastatic Melanoma: A Retrospective Database Analysis
}

\author{
Qiufei Ma - Zhongyun Zhao · Beth L. Barber - Mark Shilkrut
}

To view enhanced content go to www.advancesintherapy.com

Received: November 25, 2015 / Published online: January 21, 2016

(C) The Author(s) 2016. This article is published with open access at Springerlink.com

\begin{abstract}
Introduction: Isolated limb perfusion and infusion (ILP/ILI) are therapies for regional metastatic melanoma that allow high doses of anticancer drugs to be delivered directly into the circulation of an affected limb, thereby minimizing systemic drug toxicity. This procedure can lead to high response rates and is recommended in patients with Stage III unresectable metastatic melanoma. However, limited information is available on patterns of use and costs. This study examined patterns of ILP/ILI use and associated costs in patients with melanoma in the United States (US).
\end{abstract}

Methods: Retrospective, observational study, using administrative claims data from the MarketScan ${ }^{\circledR}$ databases, was performed in

Electronic supplementary material The online version of this article (doi:10.1007/s12325-016-0283-z) contains supplementary material, which is available to authorized users.

Q. Ma $(\bowtie) \cdot$ Z. Zhao · B. L. Barber

Global Health Economics, Amgen Inc, Thousand

Oaks, CA 91320, USA

e-mail: qma@amgen.com

M. Shilkrut

Clinical Development, Amgen Inc, Thousand Oaks,

CA 91320, USA patients with a diagnosis of melanoma (ICD-9-CM: 172.xx, V10.82) who underwent ILP/ILI (CPT-4: 36823) between January 1, 2002 and March 31, 2013. Patient characteristics, use patterns, length of hospital stay, and costs (per 2014 US \$) of ILP/ILI were assessed.

Results: One hundred and thirteen patients met the study criteria and were included in the analysis. Mean age was 61.4 years (standard deviation [SD] 13.8) and 38.9\% of patients were male; the mean baseline Charlson Comorbidity Index was $0.19 ; 34.5 \%$ of patients were Medicare beneficiaries. The majority of patients $(87.6 \%)$ had melanoma of the lower limb, $11.5 \%$ of the upper limb, and $0.9 \%$ of both limbs; $60.2 \%$ had lymph node metastasis and $56.6 \%$ had skin metastasis. Four patients (3.5\%) underwent multiple ILP/ILI. The mean $( \pm \mathrm{SD})$ length of hospital stay was $5.6( \pm 3.5)$ days and the mean $( \pm \mathrm{SD})$ cost was US\$36,758 $( \pm 27,124)$ per ILP/ILI procedure.

Conclusions: Isolated limb perfusion and infusion in patients with melanoma were associated with long hospital stays and high costs. These results provide useful source data for the economic evaluation of treatment options for regional metastatic melanoma. 
Funding: This study was funded by Amgen, Inc.

Keywords: Claims data analysis; Cost; Isolated limb infusion; Isolated limb perfusion; Melanoma; Surgery

\section{INTRODUCTION}

While melanoma accounts for approximately $5 \%$ of all skin cancers in the United States (US), it is responsible for about $90 \%$ of all skin cancer deaths [1-3]. According to the Surveillance, Epidemiology and End Results (SEER) program, the incidence of melanoma has been increasing for the last 30 years. In 2014, there were an estimated 76,100 new cases and 9710 melanoma-associated deaths in the US [4].

The goals of treatment for melanoma are cure, local control, or palliation, and are mainly determined by the stage of disease. For localized lesions (Stages I and II, American Joint Committee on Cancer, 7 th edition) removal of the tumor by wide resection is potentially curative. If there is a loco-regional recurrence following initial surgery, additional surgical attempts can be considered [24]. At a certain point, patients may be considered unresectable based on the number of failed prior attempts for surgical cure or the technical unfeasibility of additional surgery. For patients with melanoma in-transit (Stage IIIB or IIIC), the goal of treatment is maintenance of local disease control and prevention of disease progression to distant metastases, including visceral metastases (Stage IV) [5]. For patients with advanced disease, cure after surgery alone is rare. The main treatment modality for Stage IV disease is systemic drug treatment to reduce tumor burden with the aim of prolonging survival and decreasing symptoms [6].

Isolated limb perfusion (ILP) and isolated limb infusion (ILI) are therapeutic modalities for regional metastatic melanoma with prevalent in-transit disease, which allow high doses of anticancer drugs (usually chemotherapy) to be delivered directly into the circulation of an affected limb, thus minimizing systemic drug exposure and subsequent toxicity. ILP was pioneered by Creech et al. at Tulane University in the 1950s [7]. Regional concentrations of chemotherapeutic agents 15-25 times higher than those possible with systemic administration can be achieved with ILP in the tumor-bearing extremity. The isolation of the blood vessels of a limb is achieved by clamping and cannulation of the major artery and vein, and application of a tourniquet above the cannulation. ILI, a less elaborate alternative to ILP, was developed at the Sydney Melanoma Unit by Thompson et al. in the 1990s [8]. ILI differs from ILP in that it does not use an extracorporeal circulation system, making it less expensive and a shorter procedure requiring fewer medical resources. To potentiate the effect of the procedure, infusion or perfusion of the limb is frequently performed using a hyperthermic solution of chemotherapeutic agent (usually melphalan). ILP/ILI is usually performed in an inpatient setting since both procedures require anesthesia and use of an operating room.

ILP/ILI can result in response rates of 30-60\% in melanoma patients [9-11]. However, randomized clinical trials comparing ILP/ILI with other treatment modalities are lacking. ILP, as an adjunct to radical surgery, failed to demonstrate an improvement in overall 
survival in two randomized clinical trials in patients with regional metastatic melanoma $[12,13]$.

Currently, ILP/ILI is recommended by the European Society for Medical Oncology (ESMO) and the US National Comprehensive Cancer Network (NCCN) Guidelines as a treatment option for patients with unresectable in-transit melanoma [14, 15]. ESMO states that "non-resectable in-transit metastases or inoperable primary tumors of the limbs without additional metastases may be treated with ILP using, e.g., melphalan and/or tumor necrosis factor- $\alpha$ ". The NCCN states that "for patients with multiple, regional, in-transit metastases, regional chemotherapy by hyperthermic perfusion or infusion is an option". In the US, payers such as Blue Cross Blue Shield Health Plans [16-18], have established a policy that ILP/ILI should meet medical criteria for coverage when used as a therapeutic treatment for unresectable local recurrence of melanoma (i.e., satellite lesions or "in-transit" melanoma).

To date, limited information is available in the literature on patterns of ILP/ILI use and costs. This study aimed to describe patterns of ILP/ILI use and estimate associated costs in patients with regional metastatic melanoma in the US.

\section{METHODS}

\section{Data Source}

This was a retrospective, observational study using a large administrative claims database from the Truven Health Analytic MarketScan ${ }^{\circledR}$ databases. The MarketScan database contains fully adjudicated patient-level medical and pharmacy claims data for over 40 million commercially insured and Medicare-insured patients in 2014. Data elements drawn from these databases included member demographics (age, gender, residence region, and enrollment), dates of service, care setting, diagnostic codes, procedure codes, and payments.

\section{Study Population}

Patients with a diagnosis of melanoma (ICD-9-CM: 172.xx, V10.82) who underwent ILP/ILI procedures between January 1, 2002 and March 31, 2013 in an inpatient setting were included in this study. The ILP/ILI procedures were identified by the Current Procedural Terminology (CPT)-4 code 36823, which describes the procedures as "insertion of arterial and venous cannula(s) for isolated extracorporeal circulation and regional chemotherapy perfusion to an extremity, with or without hyperthermia, with removal of cannula(s) and repair of arteriotomy and venotomy sites". Admission and discharge dates were identified for each hospitalization involving an ILP/ILI procedure. At least one claim of melanoma with an ICD-9-CM diagnosis code (principal or secondary) any time between the admission and discharge dates was required to ensure that the ILP/ILI procedure was for melanoma treatment.

\section{Outcome Measures}

The main outcome measures in this analysis were patterns of ILP/ILI use, length of hospital stay (LOS), and hospitalization costs of ILP/ILI. LOS was calculated based on the number of days between the admission and discharge dates from the hospital. Costs were computed as the combined health plan and patient paid amount, and were adjusted using the annual medical care component of the consumer price index to reflect inflation between 2002 and 2014 [19]. 
Results of the analyses are presented descriptively as mean and median values. All data were analyzed using SAS programs organized within SAS $^{\circledR}$ Enterprise Guide version 4.2 (SAS Institute Inc, Cary, NC, USA) and conducted under UNIX using SAS version 9.2 .

\section{Independent Variables}

Independent variables included both demographic and clinical characteristics based on MarketScan information collected at the time of hospital admission. Demographic characteristics included in the analysis were age, gender, health plan type, Medicare or commercial beneficiaries, region, and year of service. Clinical characteristics included melanoma site, metastatic site, and Charlson Comorbidity Index score (excluding cancers) [22, 23].

This article does not contain any new studies with human or animal subjects performed by any of the authors.

\section{RESULTS}

\section{Patient Characteristics}

A total of 113 patients met the study criteria and were included in the analysis. Mean patient age was 61.4 years [standard deviation (SD) 13.8] and $38.9 \%$ of patients were male. The mean baseline Charlson Comorbidity Index score was $0.19 \%$ and $34.5 \%$ of patients were Medicare beneficiaries.

Overall, $87.6 \%$ of patients had primary melanoma of the lower limb, $11.5 \%$ of the upper limb, and $0.9 \%$ of both the upper and lower limbs; $60.2 \%$ had lymph node metastasis and $56.6 \%$ had skin metastasis within 1 year prior to the discharge date of the hospitalization. A summary of the patient demographic characteristics is reported in Table 1.

\section{Patterns of ILP/ILI Use}

Of the 113 patients identified, the majority $(109 / 113, \quad$ [96.5\%]) underwent only one procedure. Four patients (3.5\%) underwent multiple ILP/ILI procedures. Of these four patients, three underwent ILP/ILI twice, and one patient underwent three ILP/ILI procedures. The median time between procedures for these four patients was 190 days. The use of ILP/ILI was stable across years, as there was small amount of procedures (1-23) performed between 2002 and 2013.

\section{Length of Hospital Stay and Costs Associated with ILP/ILI}

Per ILP/ILI procedure, the mean $( \pm \mathrm{SD})$ hospital LOS due to ILP/ILI was $5.6( \pm 3.5)$ days. The median LOS was 5.0 days and the range was 1-22 days. From 2002 to 2013 inclusive, LOS was generally similar across the years. The mean LOS for patients with Medicare was 6.3 days, compared with 5.1 days for patients with commercial insurance.

The mean cost of ILP/ILI performed in the inpatient setting was US $\$ 36,758( \pm 27,124)$ per procedure. The range of the cost varied considerably from US\$8202 to US\$154,008, with a median cost of US\$26,905 (Table 2).

\section{DISCUSSION}

This study provides an assessment of use patterns and costs of ILP and ILI. The mean 
Table 1 Demographic and clinical characteristics of patients with melanoma who underwent ILP/ILI procedure

\begin{tabular}{|c|c|}
\hline & $\begin{array}{l}\text { Patients, } n(\%) \\
(N=113)\end{array}$ \\
\hline Age, mean (SD), years & $61.4(13.8)$ \\
\hline \multicolumn{2}{|l|}{ Age categories, years } \\
\hline $18-34$ & $2(1.8)$ \\
\hline $35-44$ & $9(8.0)$ \\
\hline $45-54$ & $27(23.9)$ \\
\hline $55-64$ & $38(33.6)$ \\
\hline $65-74$ & $14(12.4)$ \\
\hline $75+$ & $23(20.4)$ \\
\hline Female & $69(61.1)$ \\
\hline \multicolumn{2}{|l|}{ Health plan } \\
\hline Comprehensive & $24(21.2)$ \\
\hline $\mathrm{HMO}$ & $7(6.2)$ \\
\hline POS & $1(0.9)$ \\
\hline $\mathrm{PPO}$ & $67(59.3)$ \\
\hline Other plans & $14(12.4)$ \\
\hline Medicare beneficiaries & $39(34.5)$ \\
\hline \multicolumn{2}{|l|}{ Regions } \\
\hline Northeast & $11(9.7)$ \\
\hline North Central & $25(22.1)$ \\
\hline South & $62(54.9)$ \\
\hline West & $12(10.6)$ \\
\hline Unknown & $3(2.7)$ \\
\hline \multicolumn{2}{|l|}{ Primary melanoma site } \\
\hline Lower limb & $99(87.6)$ \\
\hline Upper limb & $13(11.5)$ \\
\hline Both upper and lower limbs & $1(0.9)$ \\
\hline \multicolumn{2}{|l|}{ Presence of metastasis ${ }^{a}$} \\
\hline Any metastasis & $105(92.9)$ \\
\hline Liver & $1(0.9)$ \\
\hline Lung & $3(2.7)$ \\
\hline
\end{tabular}

Table 1 continued

\begin{tabular}{lc}
\hline & $\begin{array}{c}\text { Patients, } \boldsymbol{n}(\%) \\
(\boldsymbol{N}=\mathbf{1 1 3})\end{array}$ \\
\hline Lymph nodes & $68(60.2)$ \\
Skin & $64(56.6)$ \\
Charlson Comorbidity Index & $0.19(0.49)$ \\
$\quad$ (excluding cancer), mean (SD) & \\
Year of service for ILP/ILI procedure & \\
2002 & $2(1.8)$ \\
2003 & $1(0.9)$ \\
2004 & $4(3.5)$ \\
2005 & $12(10.6)$ \\
2006 & $5(4.4)$ \\
2007 & $10(8.8)$ \\
2008 & $5(4.4)$ \\
2009 & $15(13.3)$ \\
2010 & $19(16.8)$ \\
2011 & $15(13.3)$ \\
2012 & $23(20.4)$ \\
2013 & $2(1.8)$ \\
\hline
\end{tabular}

${ }^{a}$ The site of metastases is not mutually exclusive. It was identified 1 year prior to the discharge date of the hospitalization

hospital length of stay for ILP/ILI procedures was 5.6 days and the mean cost was US\$36,758 per procedure. To the best of our knowledge, this is the first study that reports real-world use patterns and costs of ILP/ILI in a regional metastatic melanoma population in the US.

Based on the Agency for Healthcare Research and Quality (AHRQ) Healthcare Cost and Utilization Project (HCUP), the average hospital cost (physician cost not included in the report) for a surgical procedure was US $\$ 20,500$ in 2013 [20]. Therefore, the costs of ILP/ILI procedures are higher than those of an 
Table 2 Length of stay and costs associated with ILP/ILI procedures

\begin{tabular}{llllllll}
\hline & Mean (SD) & Median & Percentile & & \\
\cline { 5 - 7 } & & & 75th & 90th & 95th & 99th \\
\hline Length of stay (days) & $5.6(3.5)$ & 5.0 & 7.0 & 8.0 & 13.0 & 20.0 \\
Inpatient cost per procedure (2014 USD) & $36,758(27,124)$ & 27,556 & 47,795 & 75,741 & 93,547 & 110,485 \\
\hline
\end{tabular}

average national surgical procedure. Secondly, the LOS and costs associated with ILP/ILI procedures are in line with those associated with major surgery for metastatic melanoma as estimated by Zhao et al. [21], where the overall mean hospital LOS due to surgery was 4.4 days and the overall mean cost of hospitalization was US\$37,649.

This analysis has limitations. While ILI is currently more common than ILP, there is no separate procedure code (CPT) differentiating ILP from ILI in the claims data. This precludes an analysis of use patterns and costs separately for ILP and ILI. Cost per procedure could be different for ILP and ILI because the ILP technique involves a more technically complex and invasive operative procedure, requiring open surgical cannulation of the vessels at the root of the extremity. In comparison to ILP, ILI is a simplified and minimally invasive operative procedure. Secondly, the study population was composed of commercially insured and Medicare-insured patients, and the patterns and costs of these procedures may not be representative of all patients with regional metastatic melanoma, especially the uninsured or those covered by Medicaid. Comparison of ILP/ILI with other alternative therapies for limb melanoma metastases including electrochemotherapy, local therapies (interleukin, Rose Bengal, electrodessication), and systemic therapies was outside the scope of the current study. This topic warrants further research.
The current study focused only on hospitalization cost associated with ILP/ILI, which can be seen as direct medical costs. Indirect costs associated with ILP/ILI were not examined due to lack of indirect cost information in the database. Considering that metastatic melanoma affects the working age population, indirect costs related to the recovery period at home, concomitant medication such as antibiotics or painkillers, and rehabilitation processes could be considerable and add to the overall costs. Furthermore, the indirect cost associated with complication or morbidity due to ILP/ILI could also be substantial. Thus, the total costs of ILP/ ILI to society can be more expensive than said in the healthcare claims data.

\section{CONCLUSIONS}

The use of ILP and ILI was associated with long hospital stays and high costs. The results of this study may provide useful source data for the economic evaluation of treatment options for regional metastatic melanoma.

\section{ACKNOWLEDGMENTS}

Sponsorship, article processing charges, and the open access charge for this study were funded by Amgen, Inc. All named authors meet the International Committee of Medical Journal Editors (ICMJE) criteria for authorship for this 
manuscript, take responsibility for the integrity of the work as a whole, and have given final approval for the version to be published.

Compliance with Ethics Guidelines. This article does not contain any new studies with human or animal subjects performed by any of the authors.

Disclosures. Q Ma, Z. Zhao, B.L. Barber and M. Shilkrut are currently employed by Amgen, Inc.

Open Access. This article is distributed under the terms of the Creative Commons Attribution-NonCommercial 4.0 International License (http://creativecommons.org/licenses/ by-nc/4.0/), which permits any noncommercial use, distribution, and reproduction in any medium, provided you give appropriate credit to the original author(s) and the source, provide a link to the Creative Commons license, and indicate if changes were made.

\section{REFERENCES}

1. Cancer Facts \& Figures. American Cancer Society. http://www.cancer.org/acs/groups/content/ @research/documents/webcontent/acspc-042151.pdf (2014). Accessed 13 Sep 2014.

2. Boring CC, Squires TS, Tong T, Montgomery S. Cancer statistics, 1994. CA Cancer J Clin. 1994;44:7-26.

3. Garbe C, Peris K, Hauschild A, et al. Diagnosis and treatment of melanoma: European consensus-based interdisciplinary guideline. Eur J Cancer. 2010;46:270-83.

4. SEER (Surveillance, Epidemiology and End Results Program) Cancer Statistics Review, 1975-2011, Division of Cancer Control and Population Sciences, National Cancer Institute. http://seer. cancer.gov/csr/1975_2012. Accessed 7 Jan 2016.

5. Clinical Practice Guidelines for the Management of Melanoma in Australia and New Zealand. https:// www.nhmrc.gov.au/guidelines-publications/cp111 (2008). Accessed 22 July 2015.

6. Garbe C, Eigentler TK, Keilholz U, Hauschild A, Kirkwood JM. Systematic review of medical treatment in melanoma: current status and future prospects. Oncologist. 2011;16:5-24.

7. Creech O, Krementz E, Ryan E, Winblad J. Chemotherapy of cancer: regional perfusion utilizing an extracorporeal circuit. Ann Surg. 1958;148:616-32.

8. Thompson JF, Kam PC, Waugh RC, et al. Isolated limb infusion with cytotoxic agents: a simple alternative to isolated limb perfusion. Semin Surg Oncol. 1998;14:238-47.

9. Moreno-Ramirez D, de la Cruz-Merino L, Ferrandiz L, Villegas-Portero R, Nieto-Garcia A. Isolated limb perfusion for malignant melanoma: systematic review on effectiveness and safety. Oncologist. 2010;15:416-27.

10. Balch CM, Houghton AN, Sober AJ, Soong S. Cutaneous melanoma. St. Louis: Quality Medical Publishers; 1998. p. 282-99.

11. Kroon HM. Treatment of locally advanced melanoma by isolated limb infusion with cytotoxic drugs. J Skin Cancer. 2011;2011:106573.

12. Koops HS, Vaglini M, Suciu S, et al. Prophylactic isolated limb perfusion for localized, high-risk limb melanoma: results of a multicenter randomized phase III trial. European Organization for Research and Treatment of Cancer Malignant Melanoma Cooperative Group Protocol 18832, the World Health Organization Melanoma Program Trial 15, and the North American Perfusion Group Southwest Oncology Group-8593. J Clin Oncol. 1998;16:2906-12.

13. Hafstrom L, Rudenstam CM, Blomquist E, et al. Regional hyperthermic perfusion with melphalan after surgery for recurrent malignant melanoma of the extremities, Swedish Melanoma Study Group. J Clin Oncol. 1991;9:2091-4.

14. Dummer R, Hauschild A, Lindenblatt N, Pentheroudakis G, Keilholz U, ESMO Guidelines Committee. Cutaneous melanoma: ESMO Clinical Practice Guidelines for diagnosis, treatment and follow-up. Ann Oncol. 2015;26(Suppl 5):v126-32. doi:10.1093/annonc/mdv297.

15. National Comprehensive Cancer Network (NCCN). Practice Guidelines in Oncology: Melanoma. Version 2. http://www.nccn.org/professionals/ physician_gls/PDF/melanoma.pdf (2014). Accessed 2 Sep 2014. 
16. Blue Cross Blue Shield of Alabama. Medical Policy \#185: Isolated limb perfusion/infusion for malignant melanoma. https://www.bcbsal.org/providers/ policies/final/185.pdf (2010). Accessed 2 Dec 2014.

17. Excellus Blue Cross Blue Shield. Medical Policy \#7.01.52: Isolated limb perfusion and infusion. https://www.excellusbcbs.com/wps/wcm/connect/ c2658b4b-115a-4525-9b8e-8926a588ad83/mp+ilp+ $\mathrm{tac}+15$.pdf?MOD=AJPERES\&CACHEID $=\mathrm{c} 2658 \mathrm{~b} 4 \mathrm{~b}-$ 115a-4525-9b8e-8926a588ad83 (2014). Accessed 7 Jan 2016.

18. Capital Blue Cross Blue Shield. Medical Policy \# MP-1.079: Isolated limb perfusion/infusion for malignant melanoma. September 1. https://www. capbluecross.com/wps/wcm/connect/f3569534-936 e-42b5-be06-deda2a3cfcd9/IsolatedLimbPerfusionInfusionforMalignantMelanomaMP-1.079-7-30-13. pdf?MOD=AJPERES (2013). Accessed 2 Dec 2014.

19. US Department of Bureau of Labor Statistics. Consumer price index. Chained consumer price index for all urban consumers (C-CPI-U) 2004-2014, Medical Care. Series ID: SUUR0000SAM. Washington, DC: U.S. Dept. of Labor, Bureau of Labor Statistics. http://data.bls. gov/cgi-bin/surveymost?su (2014). Accessed 8 Dec 2014 .
20. Healthcare Cost and Utilization Project (HCUP) Cost of Inpatient Discharges 2003 to 2013. U.S. Agency for Healthcare Research and Quality, Rockville, MD. http://www.hcup-us.ahrq.gov/ reports/projections/2013-01.pdf. Accessed 2 Dec 2014.

21. Zhao Z, Wang S, Barber B. The pattern and cost of palliative surgeries in patients with metastatic melanoma. Poster Presentation, Society for Melanoma Research (SMR). November 8-11, 2012. Hollywood, CA, USA.

22. Deyo RA, Cherkin DC, Ciol MA. Adapting a clinical comorbidity index for use with ICD-9-CM administrative databases. J Clin Epidemiol. 1992;45:613-9.

23. Charlson ME, Pompei P, Ales KL, MacKenzie CR. A new method of classifying prognostic comorbidity in longitudinal studies: development and validation. J Chronic Dis. 1987;40:373-83.

24. Edge SB, Byrd DR, Compton CC, Fritz AG, Greene FL, Trotti A, editors. AJCC cancer staging manual. 7th ed. New York: Springer; 2010. 